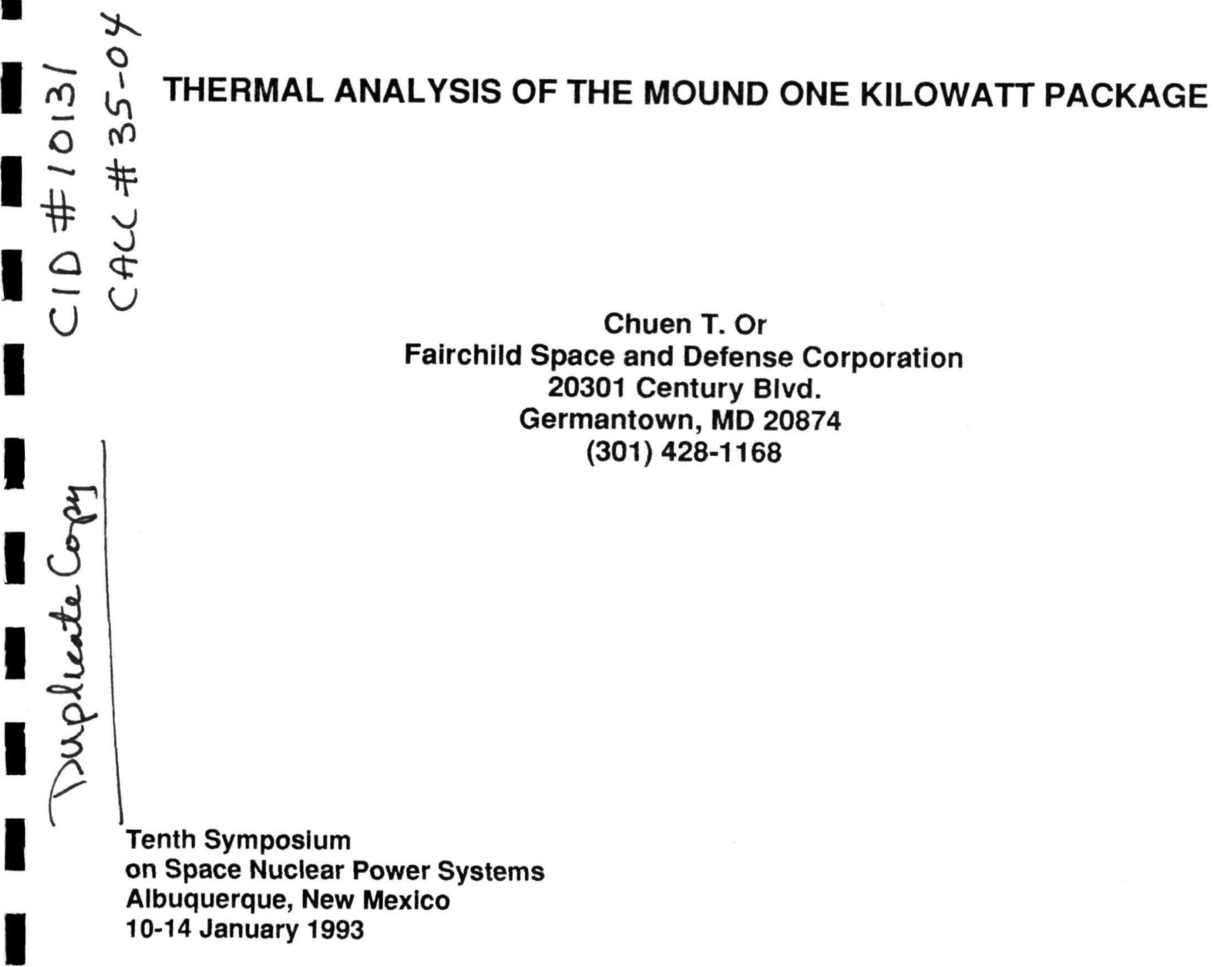




\section{DISCLAIMER}

This report was prepared as an account of work sponsored by an agency of the United States Government. Neither the United States Government nor any agency Thereof, nor any of their employees, makes any warranty, express or implied, or assumes any legal liability or responsibility for the accuracy, completeness, or usefulness of any information, apparatus, product, or process disclosed, or represents that its use would not infringe privately owned rights. Reference herein to any specific commercial product, process, or service by trade name, trademark, manufacturer, or otherwise does not necessarily constitute or imply its endorsement, recommendation, or favoring by the United States Government or any agency thereof. The views and opinions of authors expressed herein do not necessarily state or reflect those of the United States Government or any agency thereof. 


\section{DISCLAIMER}

Portions of this document may be illegible in electronic image products. Images are produced from the best available original document. 


\title{
THERMAL ANALYSIS OF THE MOUND ONE KILOWATT PACKAGE
}

\author{
Chuen T. Or \\ Fairchild Space and Defense Corporation \\ 20301 Century Blvd. \\ Germantown, MD 20874 \\ (301) 428-1168
}

Tenth Symposium

on Space Nuclear Power Systems

Albuquerque, New Mexico

10-14 January 1993 
THERMAL ANALYSIS OF THE MOUND ONE KILOWATT PACKAGE

\author{
Chuen T. Or \\ Fairchild Space and Defense Corporation \\ 20301 Century Blvd. \\ Germantown, MD 20874 \\ (301) $428-1168$
}

\begin{abstract}
The Mound One Kilowatt ( $1 \mathrm{~kW}$ ) package was designed for the shipment of plutonium (Pu-238) with not more than $1 \mathrm{~kW}$ total heat dissipation. To comply with regulations, the Mound $1 \mathrm{~kW}$ package has to pass all the requirements under Normal Conditions of Transport (NCT; $38^{\circ} \mathrm{C}$ ambient temperature) and Hypothetical Accident Conditions (HAC; package engulfed in fire for $\mathbf{3 0}$ minutes). Analytical and test results were presented in the Safety Analysis Report for Packaging (SARP) for the Mound $1 \mathrm{~kW}$ package, revision 1, April 1991. Some issues remained unresolved in that revision. In March 1992, Fairchild Space and Defense Corporation was commissioned by the Department of Energy to perform the thermal analyses. 3-D thermal models were created to perform the NCT and HAC analyses. Four shipping configurations in the SARP revision 3 were analyzed. They were: (1) The GPHS graphite impact shell (GIS) in the threaded product can (1000 W total heat generation); (2) The fueled clads in the welded product can (1000 W total heat generation); (3) The General Purpose Heat Source (GPHS) module (750 W total heat generation); and (4) The Multi-Hundred Watt (MHW) spheres ( $810 \mathrm{~W}$ total heat generation). Results from the four cases show that the GIS or fuel clad in the product can is the worst case. The temperatures predicted under NCT and HAC in all four cases are within the design limits. The use of helium instead of argon as cover gas provides a bigger safety margin.
\end{abstract}

\title{
BACKGROUND
}

The Mound One Kilowatt ( $1 \mathrm{~kW}$ ) package was designed for the shipment of plutonium (Pu-238) with not more than $1 \mathrm{~kW}$ total heat dissipation. To comply with regulations, the Mound $1 \mathrm{~kW}$ package has to pass all the requirements under Normal Conditions of Transport (NCT; $38^{\circ} \mathrm{C}$ ambient temperature) and Hypothetical Accident Conditions (HAC; package engulfed in fire for 30 minutes). In the Safety Analysis Report for Packaging (SARP) for the Mound $1 \mathrm{~kW}$ package written in April 1991 (Coleman 1991), PAI Corporation's temperature predictions from analyses were substantially lower than those predicted by the reviewers from Lawrence Livermore National Laboratory.

To resolve the differences, H\&R Technical Associates, Inc. were commissioned by EG\&G Mound Applied Technologies to perform the thermal analyses. However, their 2-D axisymmetric model was deemed inadequate in predicting accurate temperatures. In March 1992, Fairchild Space and Defense Corporation was commissioned by DOE to perform the worst case thermal analyses. Subsequently, all four cases to be included in the SARP revision 3 were analyzed by Fairchild personnel. Results and discussion of the four cases analyzed are presented.

\section{PHYSICAL INFORMATION OF MOUND 1 KW PACKAGE}

The Mound $1 \mathrm{~kW}$ package consists of a stainless steel frame and wire mesh personnel shield (cage) that completely encloses a stainless steel cask. Figure 1 shows the assembled package. Inside the cask is the welded leaktight Secondary Containment Vessel (SCV). Inside the SCV are the welded leaktight Primary Containment Vessels (PCVs). Figure 2 shows the confinement boundary of the package and the two levels of containment.

The containment vessels can hold three possible content configurations. The first configuration is a General Purpose Heat Source (GPHS) module. The second configuration holds Multi-Hundred Watt (MHW) Fuel Sphere Assemblies (FSAs). The third configuration is designed to hold a maximum of either sixteen GPHS fueled clad assemblies in welded cans, eight plutonium dioxide powder cans in threaded product cans, or eight GPHS Graphite Impact Shell (GIS) assemblies in threaded product cans. The cage is made of type 304 stainless steel except the structural tubes at the base which are made of type A-500 carbon steel. The cask, SCV, PCVs, and product cans are all made of type 304L stainless steel. 


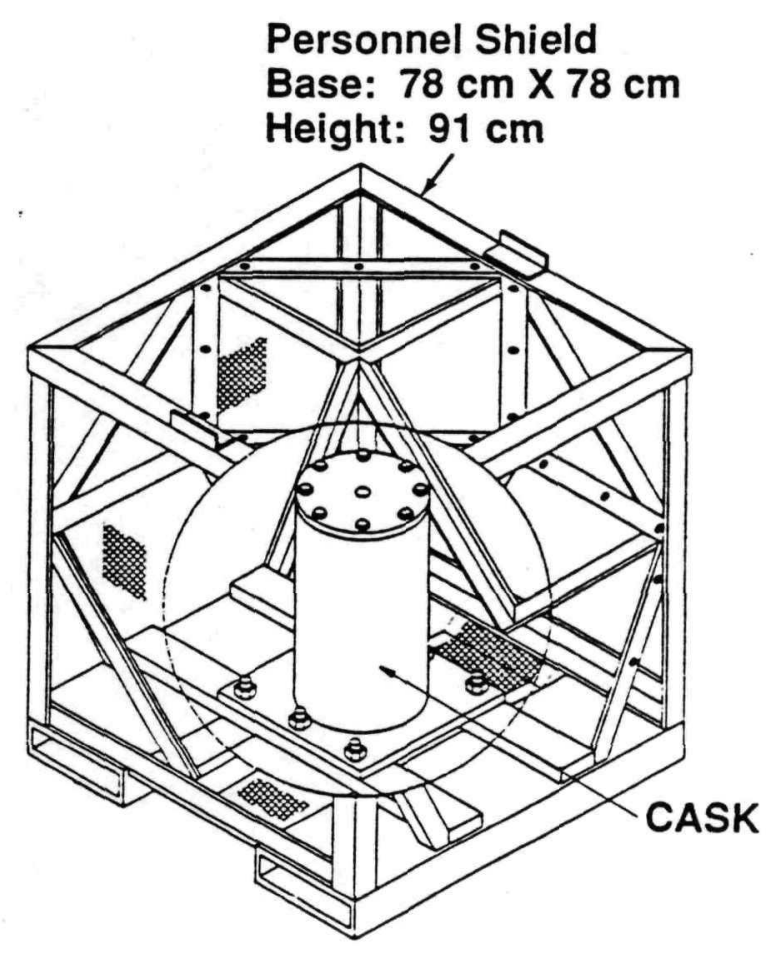

FIGURE 1. Mound $1 \mathrm{~kW}$ Package (Excerpt from Coleman 1991)

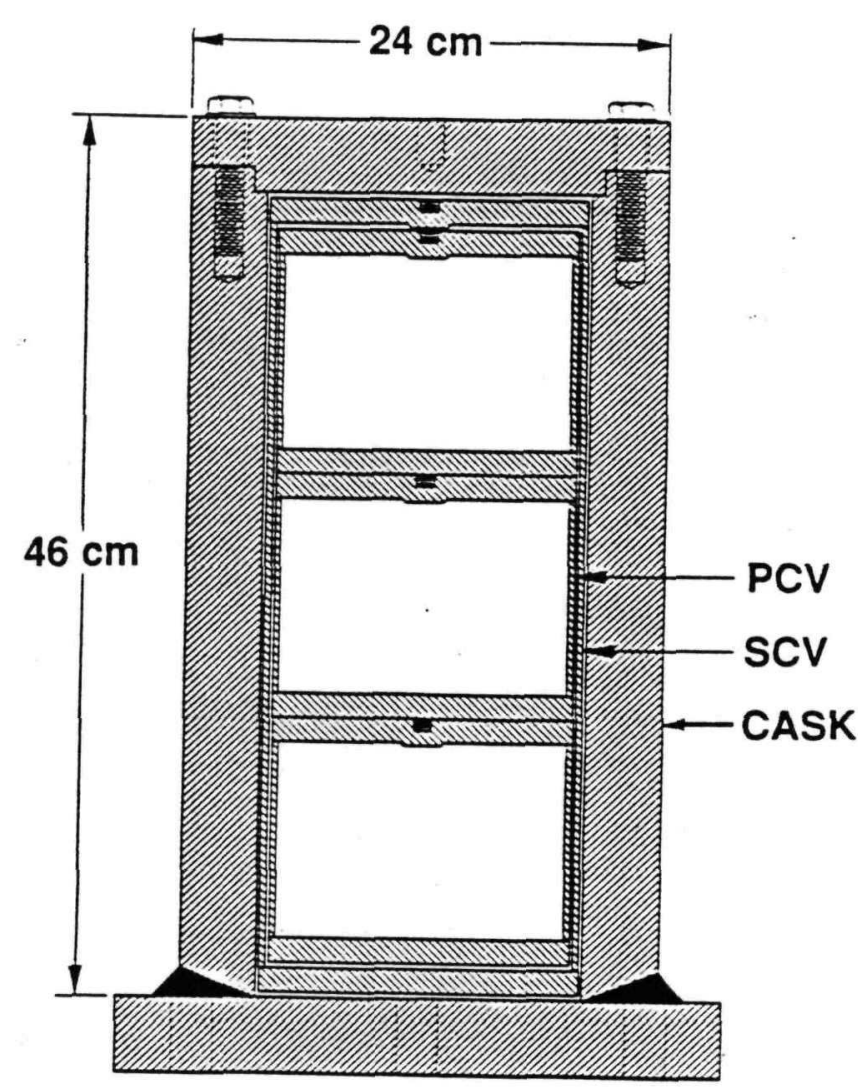

FIGURE 2. Cut-away View of Cask and Containment Vessels (Excerpt from Coleman 1991)

The GPHS module is shipped in $12.7 \mathrm{~cm}$ (5 inch) tall PCVs. The GPHS module is held in position by a graphite support block. The graphite support block basically is a cylindrical block designed to snugly fit inside the PCV. The block has a rectangular hole in the middle to house the GPHS module. Once assembled, three of the $12.7 \mathrm{~cm}$ tall PCVs can be placed into the SCV.

MHW FSAs are shipped in $12.7 \mathrm{~cm}$ tall PCVs. Up to three MHW FSAs are shipped in a single PCV. A 304L stainless steel sphere separator is used to space the spheres equally. A graphite filler block is used to fill excess void space. Three of the $12.7 \mathrm{~cm}$ tall PCVs can be loaded into a single SCV.

The threaded and/or welded product cans are shipped in $14.6 \mathrm{~cm}(5.75$ inch) tall PCVs. Two $14.6 \mathrm{~cm}$ PCVs are placed in a single SCV with a graphite block used as a spacer. Four or fewer product cans are shipped in a single PCV. To space the cans and prevent movement, the product cans are placed in the four cylindrical holes in a graphite support block.

Longitudinal section of the four shipping configurations analyzed are shown from Figures 3 to 6 . (NCT temperatures predicted are also shown.) 


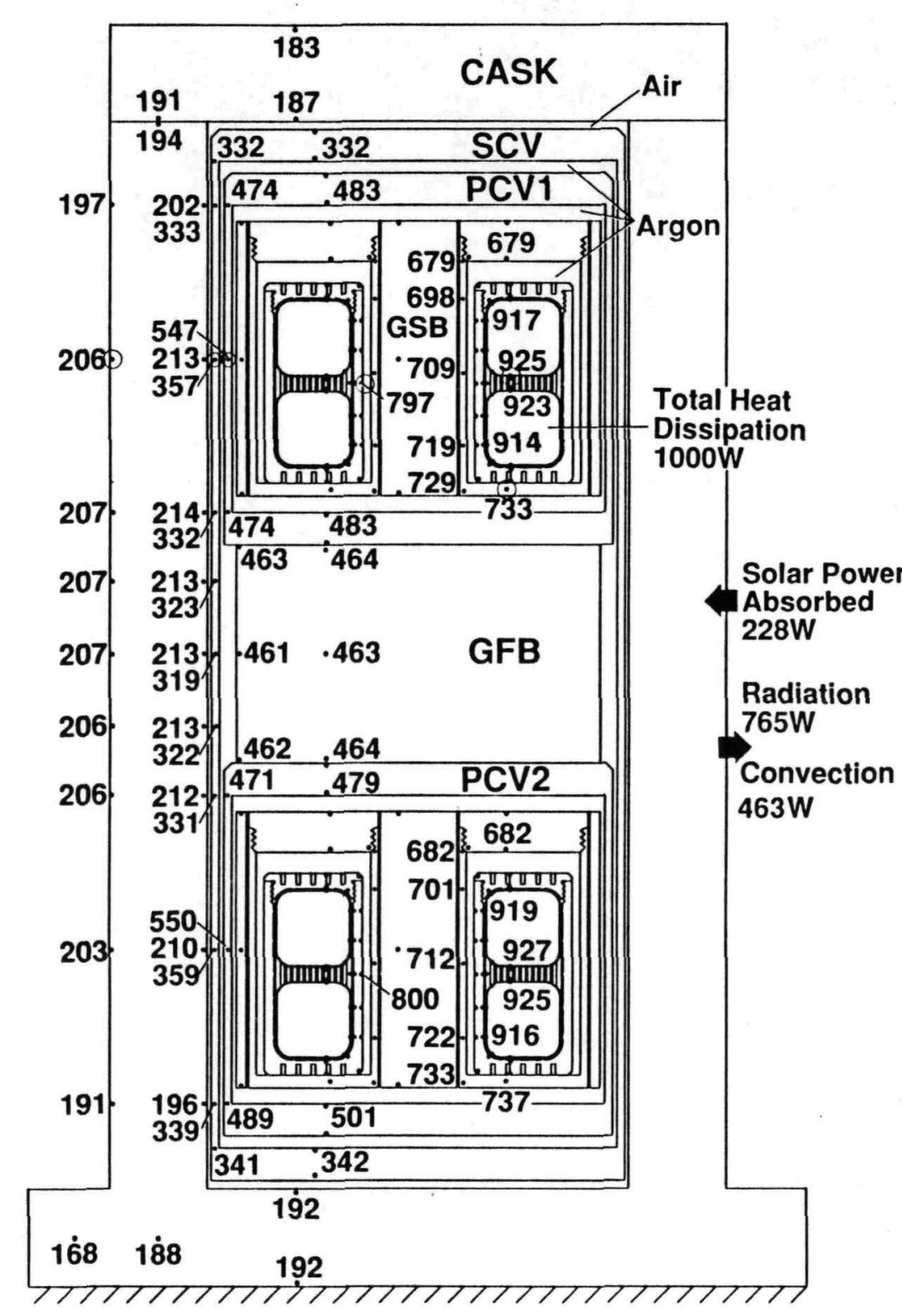

FIGURE 3. Steady State Temperatures of 8-GiS Model

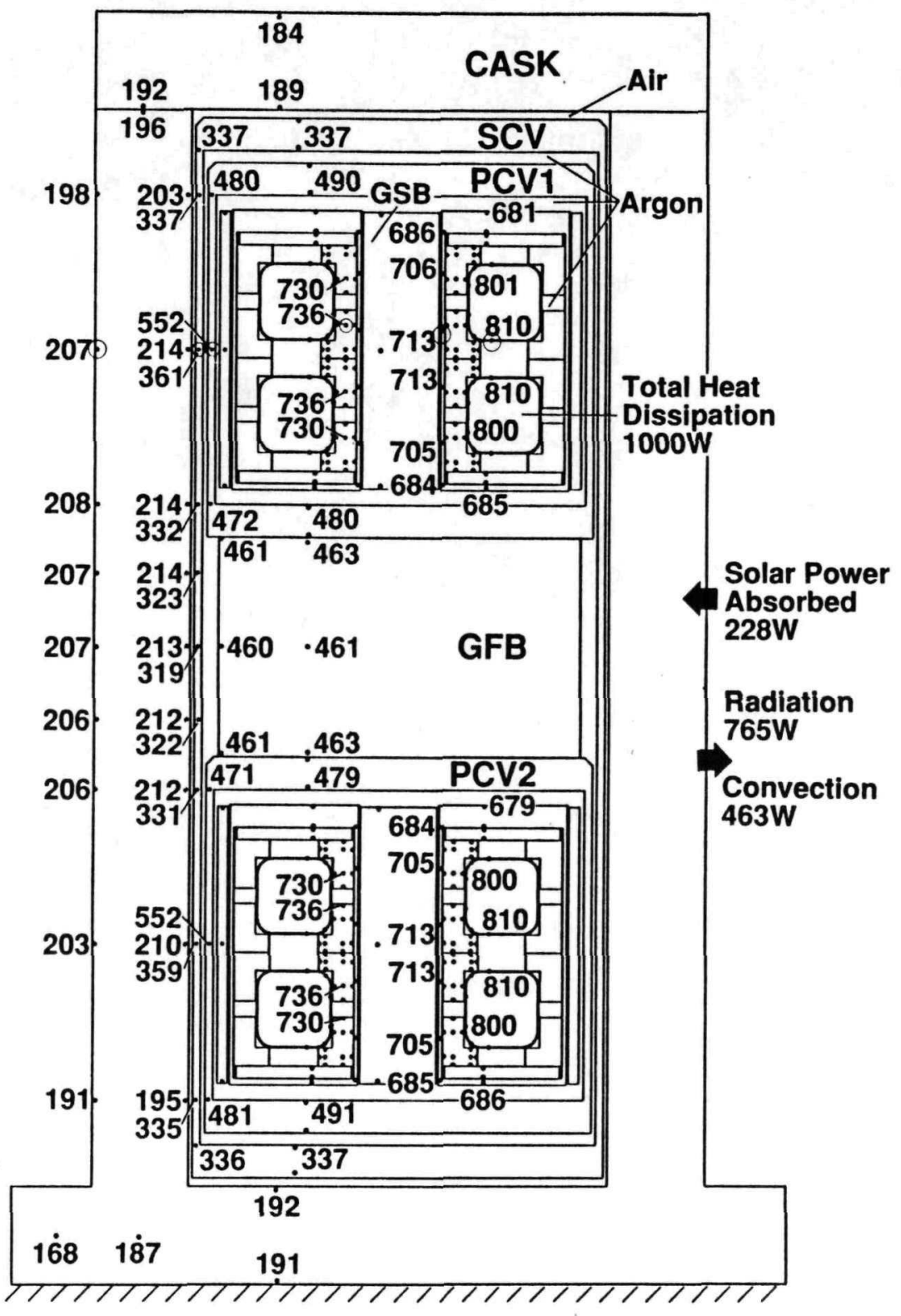

FIGURE 4. Steady State Temperatures of 16-Clad Model 


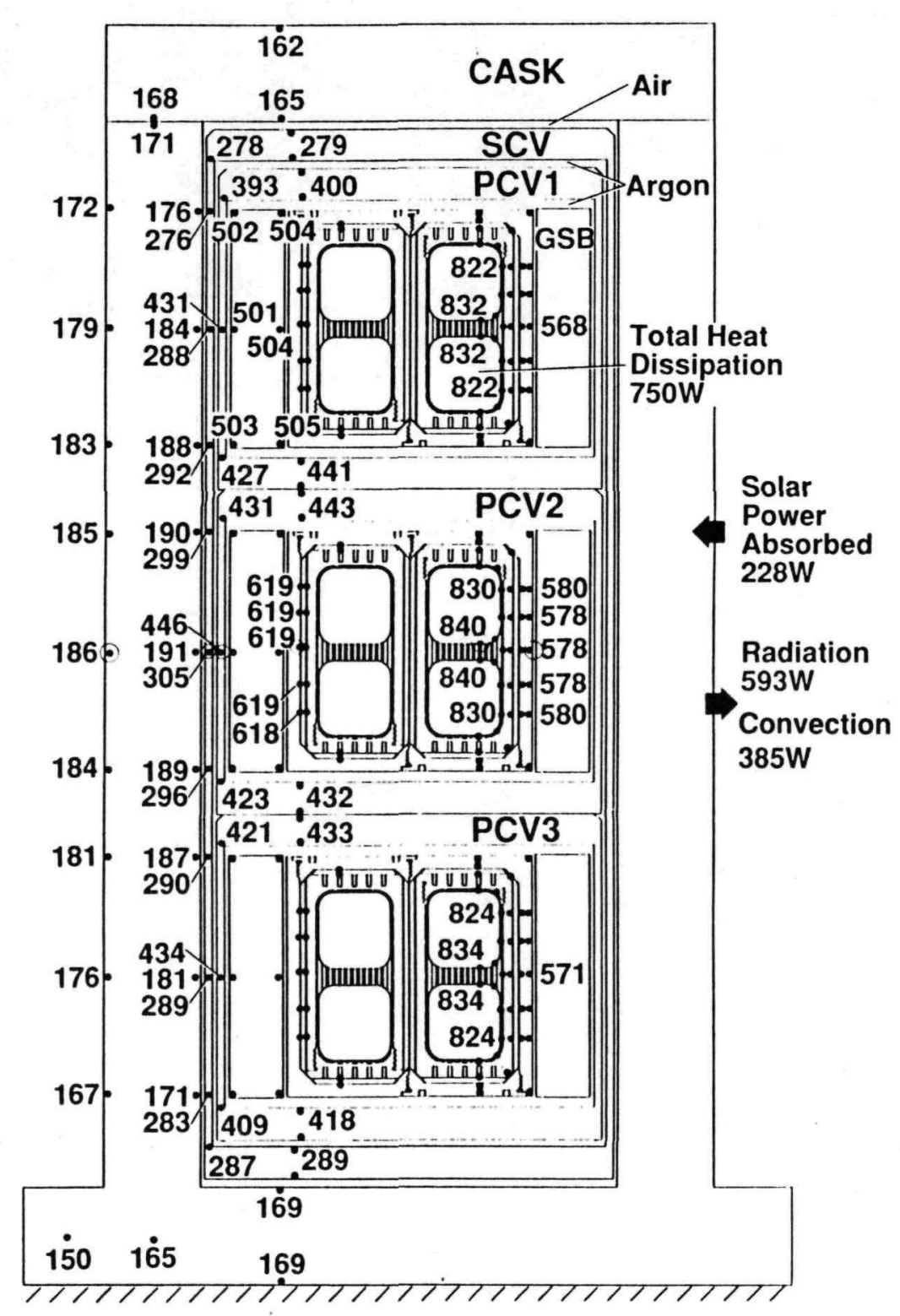

FIGURE 5. Steady State Temperatures of 3-GPHS Model

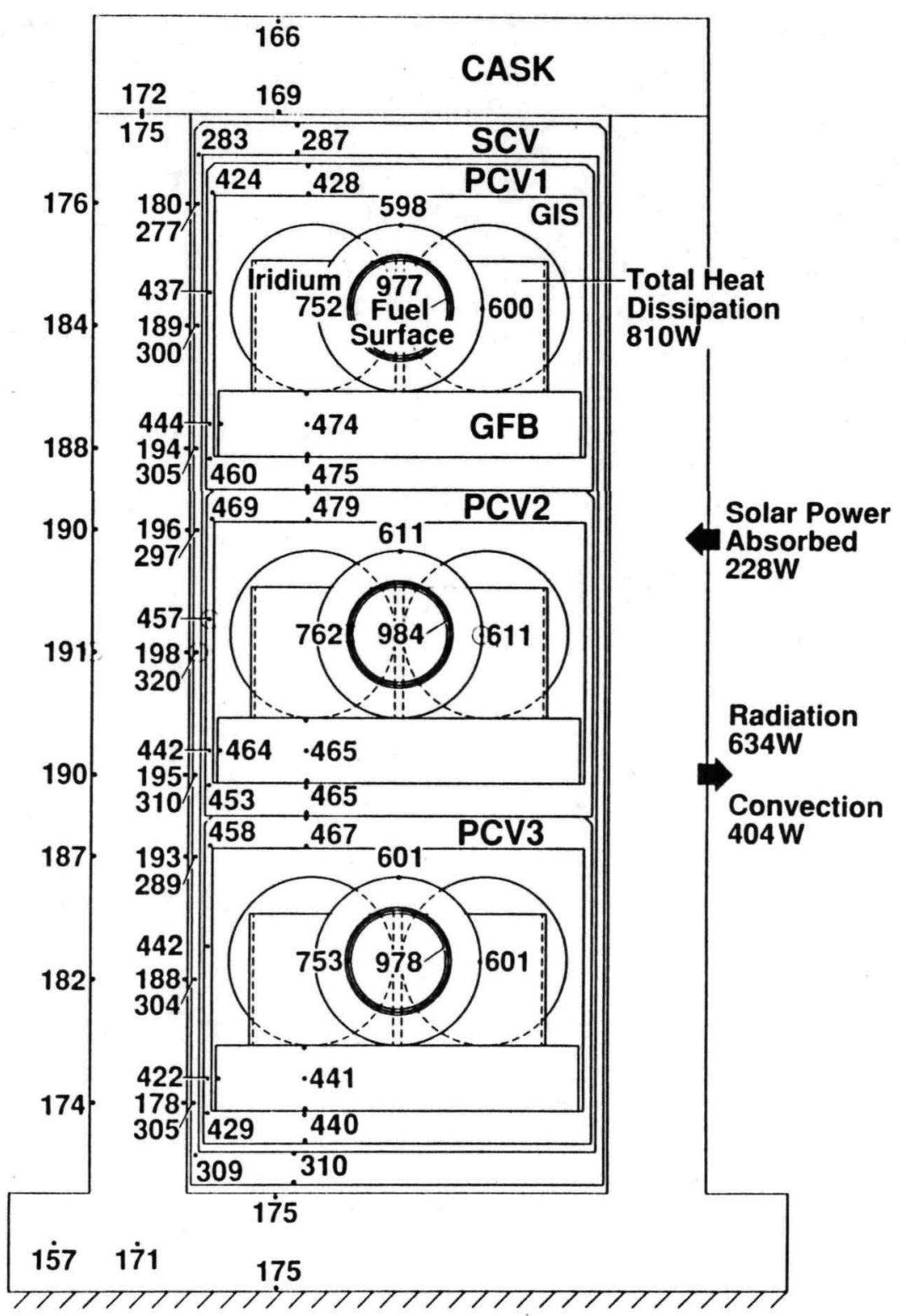

FIGURE 6. Steady State Temperatures of 9-MHW Model 
The ultimate strength of $304 \mathrm{~L}$ stainless steel at $843^{\circ} \mathrm{C}\left(1550^{\circ} \mathrm{F}\right)$ is approximately $83 \mathrm{MN} / \mathrm{m}^{2}(12,000 \mathrm{psi})$. However at temperatures above $538^{\circ} \mathrm{C}\left(1000^{\circ} \mathrm{F}\right) 304 \mathrm{~L}$ stainless steel begins to show creep and stress rupture characteristics, and at $816^{\circ} \mathrm{C}\left(1500^{\circ} \mathrm{F}\right)$ its behavior can become very plastic. Therefore, to maintain the structural integrity of the containment vessels (PCVs and SCV) under normal conditions of transport, the maximum temperatures of the vessels should not exceed $538^{\circ} \mathrm{C}$ (creep limit). To maintain confinement under hypothetical accident conditions, the vessels should not exceed $816^{\circ} \mathrm{C}$ (plastic limit).

An additional loading restriction is required to assure the maximum pressure buildup in a PCV remains below the allowable pressure. The allowable pressure is the pressure in a PCV under Hypothetical Accident Conditions (HAC) above which localized secondary stresses can exceed the ultimate strength of the PCV material.

The pressure increase in a PCV results from thermal expansion of the argon cover gas and helium generated from the alpha decay of the plutonium. To limit buildup of helium, a restriction of one year is placed on the length of time that the PCV can be welded shut before shipment.

\section{THERMAL MODELS}

A finite difference computer code called SINDA (System Improved Numerical Differencing Analyzer) (Gaski 1986) was used to perform the thermal analyses. Where necessary, SSPTA (Simplified Space Payload Thermal Analyzer) (Little 1986) was used to calculate the radiation exchange between surfaces.

The following four shipping configurations were analyzed in turn to determine the package temperatures and pressures for normal conditions of transport (NCT) and hypothetical accident conditions (HAC):

1. The GPHS graphite impact shell (GIS) in the threaded product can (1000 $\mathrm{W}$ total heat generation);

2. The fueled clads in the welded product can (1000 W total heat generation);

3. The GPHS module ( $750 \mathrm{~W}$ total heat generation); and

4. The MHW spheres ( $810 \mathrm{~W}$ total heat generation).

3-D models were created for each of the above four configurations. The 8-GIS model without the cage was first created to predict the time varying temperature distributions in HAC. It was speculated by Fairchild personnel to be the worst case. The same model was used to predict the NCT temperatures conservatively without taking credit of cooling by the cage.

From the cask outer surface, both radiation and convection heat transfer are included in the models in both NCT and HAC calculations. Constant wall temperature was assumed for convection to and from the cask wall. From Kays and Crawford for laminar flow on a vertical wall (Kays 1980)

$$
\mathrm{Nu}_{(\mathrm{x})}=3 / 4\left[2 \mathrm{Pr} / 5\left(1+2 \mathrm{Pr}^{1 / 2}+2 \mathrm{Pr}\right)\right]^{1 / 4}\left[\mathrm{Gr}(\mathrm{x}) \mathrm{Pr}^{1 / 4}\right.
$$

where Nu, Pr, Gr are the Nusselt, Prandtl, and Grasshoff numbers respectively. In this equation they are all local properties. The equation leads to

$$
\mathrm{H}(\mathrm{x}) \alpha \mathrm{x}^{-1 / 4} \text {. }
$$

The convective heat transfer coefficient $\mathrm{H}$ is a weak function of the axial distance $\mathrm{x}$. Therefore, for simplicity in modelling, the average heat transfer coefficient was used for the cask wall. Integrating along the wall, the average Nusselt number $\mathrm{Nu}$ is

$$
\mathrm{Nu}=\left[2 \mathrm{Pr} / 5\left(1+2 \mathrm{Pr}^{1 / 2}+2 \mathrm{Pr}\right)\right]^{1 / 4}[\mathrm{Gr} \cdot \mathrm{Pr}]^{1 / 4} \quad \mathrm{Gr}<10^{9}
$$


For the convective heat transfer for cask top and cask baseplate, from Gebhart (Gebhart 1971):

1. For horizontal surfaces facing upward

$$
\begin{array}{ll}
\mathrm{Nu}=0.54(\mathrm{Gr} \cdot \mathrm{Pr})^{1 / 4} & 10^{5}<\mathrm{Gr} \cdot \mathrm{Pr}<10^{7} \\
\mathrm{Nu}=0.14(\mathrm{Gr} \cdot \mathrm{Pr})^{1 / 3} & 10^{7}<\mathrm{Gr} \cdot \operatorname{Pr}<3 \times 10^{10}
\end{array}
$$

2. For horizontal surfaces facing downward

$$
\mathrm{Nu}=0.27(\mathrm{Gr} \cdot \mathrm{Pr})^{1 / 4} \quad 3 \times 10^{5}<\mathrm{Gr} \cdot \mathrm{Pr}<3 \times 10^{10}
$$

where the length scale $=$ surface area/perimeter. (Results from thermal analyses were checked to confirm that the Grasshoff numbers were within ranges specified.)

Inside the cask, only radiation and conduction heat transfer were included in the model. Convection through the small gaps is negligible compared with conduction. In the thermal model, the thermal conductivity of all solids and gases, and the kinematic viscosity and bulk modulus of air are varying with temperature. Consequently, the thermal conductances and the convective heat transfer coefficients are updated in every iteration.

In the transient analyses, the same models used for steady state analyses were used. Heat capacitance of all solids were added. Time varying environments were switched accordingly for the initial conditions, cask engulfed in fire, and cask after the fire. All the temperature dependent properties described above were updated in every output time step specified.

\section{RESULTS AND DISCUSSION}

\section{The Worst Case}

When the task was first given, Fairchild's role was to perform an independent thermal analysis of the worst case. The biggest concerns were that in the transient fire test (HAC) the PCV temperatures may exceed the plastic limit of $816^{\circ} \mathrm{C}$ and the iridium clad temperature may exceed the grain growth temperature of $1300^{\circ} \mathrm{C}$. Under these concerns, the 8 GPHS GIS (shown in Figure 3 ) was believed to be the worst shipping configuration.

In the HAC, regulations required the package to go through a 9 meter ( 30 foot) drop before the fire. In previous testing and analysis (Coleman 1991), the cage was severely damaged after the drop test. The cask was thermally decoupled from the cage. Therefore, only the cask is required to go through the fire tests. For simplicity in the modeling, cooling by the cage was not credited to set the initial cask temperatures before the fire. In the analysis, the cask was levitating in a room (no solar insolation ), convecting to $38^{\circ} \mathrm{C}\left(100^{\circ} \mathrm{F}\right.$ ) air and radiating to $38^{\circ} \mathrm{C}$ wall.

Then the cask was levitating in a large furnace of $802^{\circ} \mathrm{C}\left(1475^{\circ} \mathrm{F}\right)$ wall and $802^{\circ} \mathrm{C}$ air for 30 minutes. To account for black soot covering the cask, emissivity of cask outer surfaces was increased from 0.7 to 0.8 . Then the cask was moved back to the room for cooling. Figure 7 shows the temperature variation with time of each component at the hottest locations. As shown, the maximum temperature of the PCV of $701^{\circ} \mathrm{C}$ is much lower than the $816^{\circ} \mathrm{C}$ plastic limit, and that of iridium clad of of $998^{\circ} \mathrm{C}$ is much lower than the $1300^{\circ} \mathrm{C}$ grain growth limit. Therefore both PCVs and SCV do not fail in the fire and iridium clads and the fuel pellets are reusable after the fire.

In the NCT, regulations required that the PCV can be sealed for up to one year, and that the package must be capable of withstanding exposure to an ambient temperature of $38^{\circ} \mathrm{C}$ in still air with solar insolation without substantial reduction in the effectiveness of the package.

NCT analyses were performed with the existing bare cask model originally created for HAC. NCT temperature predictions were performed by steady state analyses in which solar insolation was applied; the cask was placed on an adiabatic surface radiating and convecting to a $38^{\circ} \mathrm{C}$ environment. Again, cooling by the cage was not credited. The predictions are conservative. 


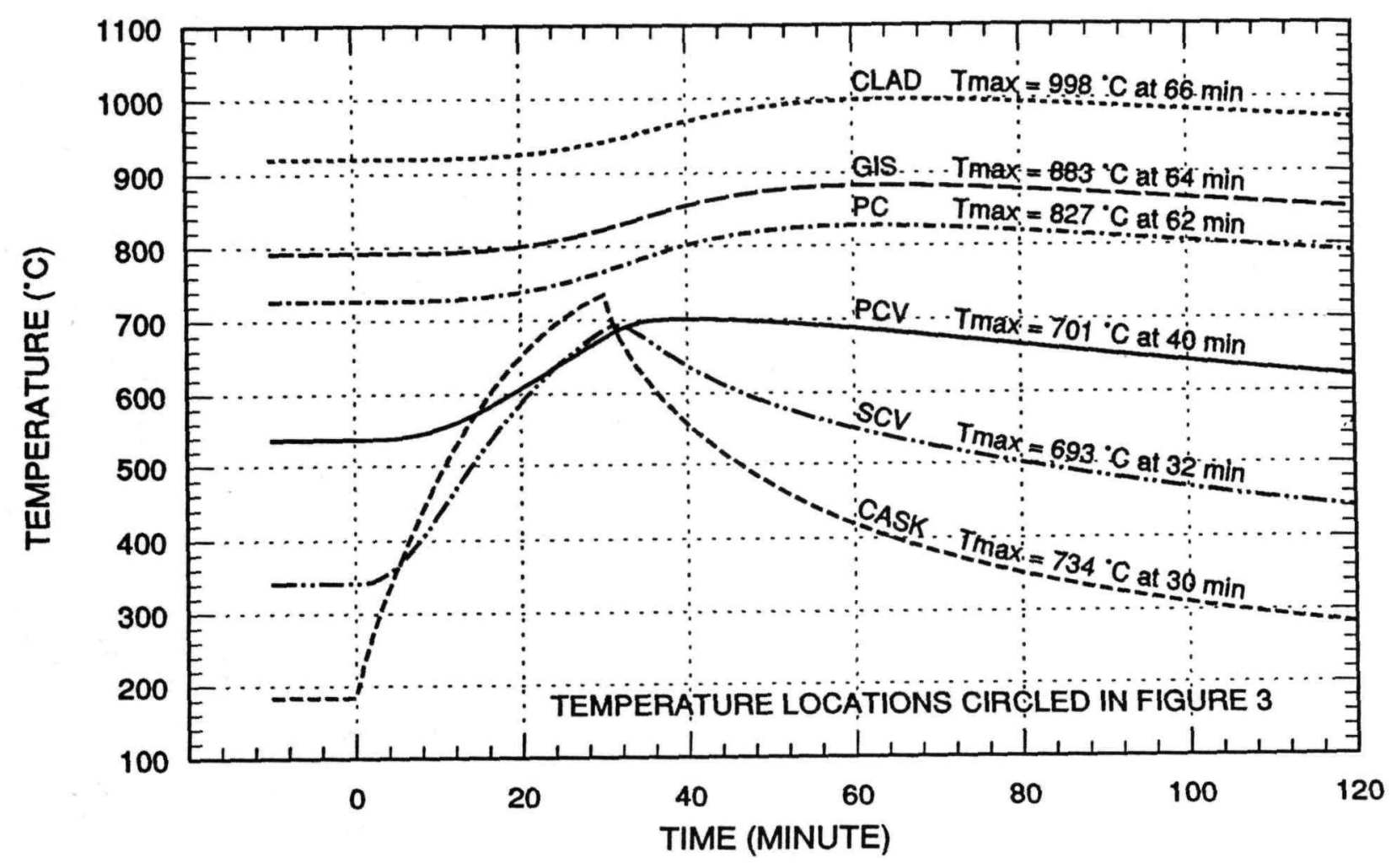

FIGURE 7. Transient Temperatures of 8-GIS Model

As shown in Figure 3, the maximum PCV temperature of $550^{\circ} \mathrm{C}$ is slightly above the creep limit of $538^{\circ} \mathrm{C}$. Creeping results in enlargement of PCV which in turn would reduce the gap size between PCV and SCV. Temperature drops across the gap and hence the PCV temperatures would decrease. Consequently creeping in the PCV has its own stabilizing effect. Also, creeping is limited by the confinement of the thick cask wall. Therefore creep failure is prevented.

Besides creeping, thermal stresses resulting from differential thermal expansions and intemal pressure increases were calculated by EG\&G (Coleman 1992) to make sure the maximum limit was not exceeded. The containment vessel internal pressure increases because the trapped cover gas is at a lower temperature in the weld shut process than when the vessel is in the cask. Helium gas generation by $\alpha$-decay also contributes to the pressure increases. In the temperature predictions, pure argon cover gas was used. In the internal pressure increase calculations, maximum amount of helium gas generations for one year was used. Both assumptions are for the worst cases. For the 8-GIS shipping configurations, results shows that the maximum thermal stresses for both NCT and HAC have not exceeded the allowable stress limit (see Table 2.5, 2.6, 2.7, 2.8, 2.9, and 2.22a in SARP Revision 3, Coleman 1992).

\section{The Other Shipping Configurations}

The 16-clad, 3-GPHS, and 9-MHW shipping configurations were analyzed in turn. Results are shown in Figures 4 to 6 for NCT, and Figures 8 to 10 for HAC. The 16-clad case is similar to the 8-GIS case with the same SCV, PCV, graphite support block, and the same heat dissipations. The case was analyzed because, like the 8-GIS, the 16-clad case is the worst case with respect to the containment vessels, and the fuel is much more likely to be shipped in the 16-clad than the 8-GIS configuration. Steady state analysis and transient fire analysis results are shown in Figures 4 and 8, respectively. Comparing Figures 3 and 4, and Figures 7 and 8, the cask, SCV, and PCV temperatures are about the same. The clad temperatures in the 16-clad configuration is much lower than those of the 8-GIS configuration because in the former case, the clads can radiate to the product can directly. 


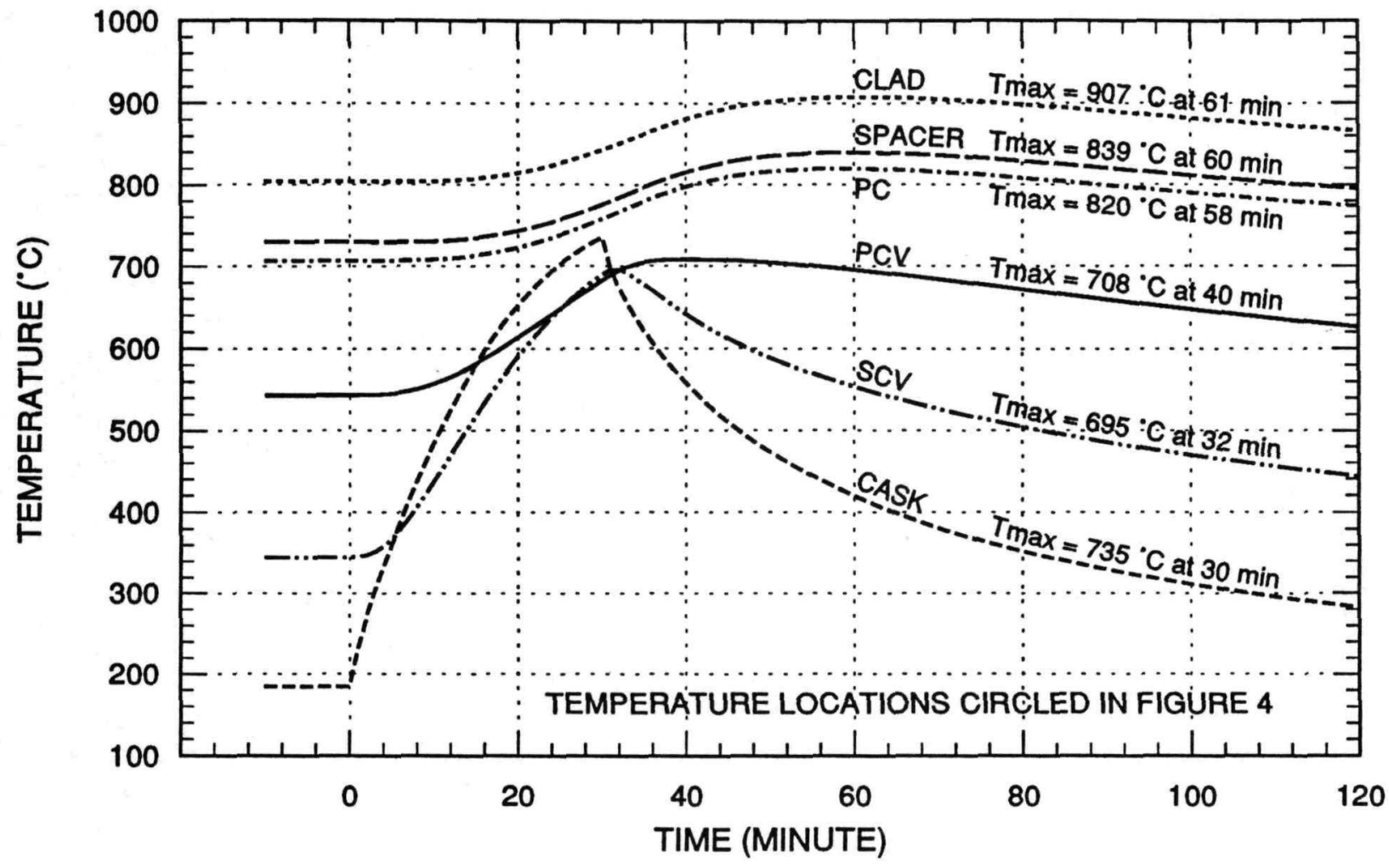

FIGURE 8. Transient Temperatures of 16-Clad Model

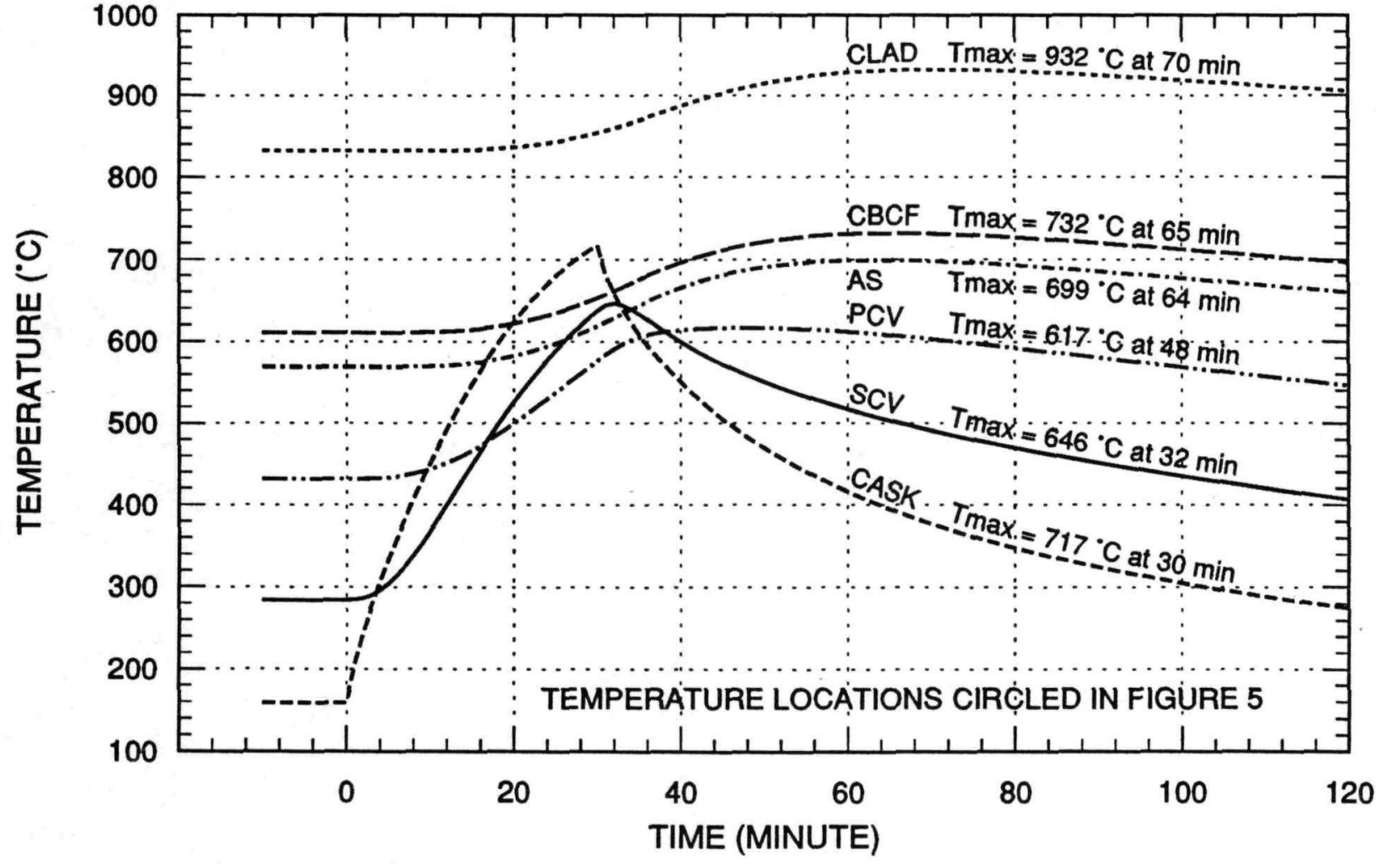

FIGURE 9. Transient Temperatures of 3-GPHS Model 


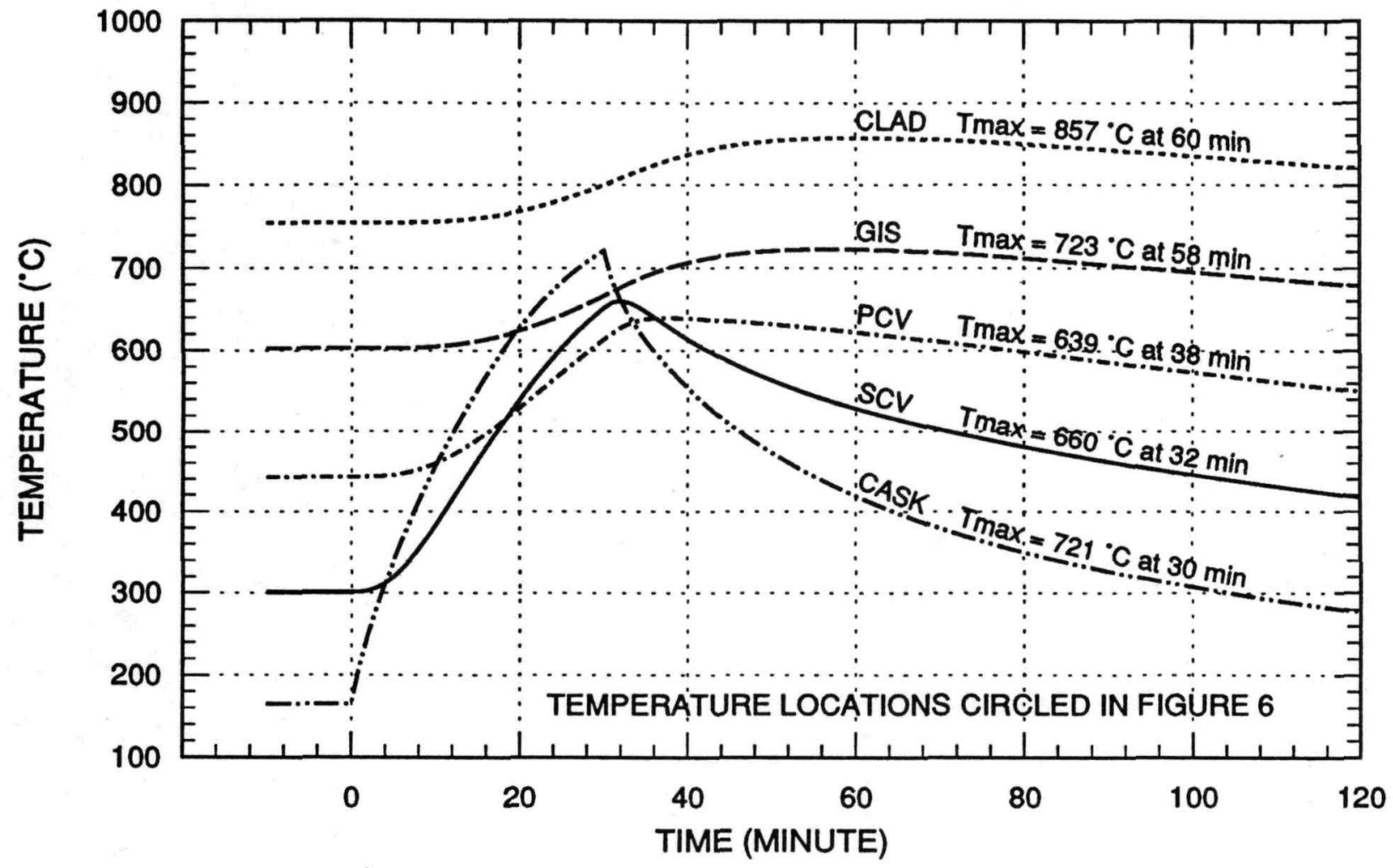

FIGURE 10. Transient Temperatures of 9-MHW Model

The 3-GPHS configuration was included for benchmark comparison with tests and with predictions from other agencies. The 9-MHW configuration was analyzed because the SARP reviewers raised the concern that since 810 $\mathrm{W}$ total heat dissipation from the 9-MHW spheres is not substantially lower than the $1000 \mathrm{~W}$ from the 8-GISs, the middle PCV in the 9-MHW configuration could be hotter than the PCVs at the ends in the 8-GIS configurations. Results show that in NCT even though the middle PCV in a 9-MHW configuration is about $20^{\circ} \mathrm{C}$ hotter than the PCVs at the ends, its temperature is about $100^{\circ} \mathrm{C}$ colder than the 8-GIS PCV. Therefore, Fairchild's prediction that product can case is the worst case is confirmed.

The shipping configuration in which plutonium dioxide powder cans are encapsulated in threaded product cans was not analyzed thermally because the amount of heat generated by the powder (approximately $460 \mathrm{~W}$ total per package) is small relative to the shipping configurations analyzed ( $750 \mathrm{~W}$ to $1000 \mathrm{~W}$ total per package).

\section{Refined Model Accounting for Differential Thermal Expansions}

All the dimensions used in the thermal models were based on specifications at room temperature. Since the inner containment vessels are much hotter than the outer containment vessels, the inner vessels expand more than the outer vessel. That means the gaps between the vessels are smaller when fuel is being contained. The smaller gap leads to a smaller temperature difference across the gap which leads to lower containment vessel temperatures. The effect of differential thermal expansions is added to refine the thermal model. Results are shown in Figure 11. Comparing results from Figure 3, the maximum PCV temperature has dropped $23^{\circ} \mathrm{C}$ to $527^{\circ} \mathrm{C}$ which is lower than the $538^{\circ} \mathrm{C}$ creep limit. 


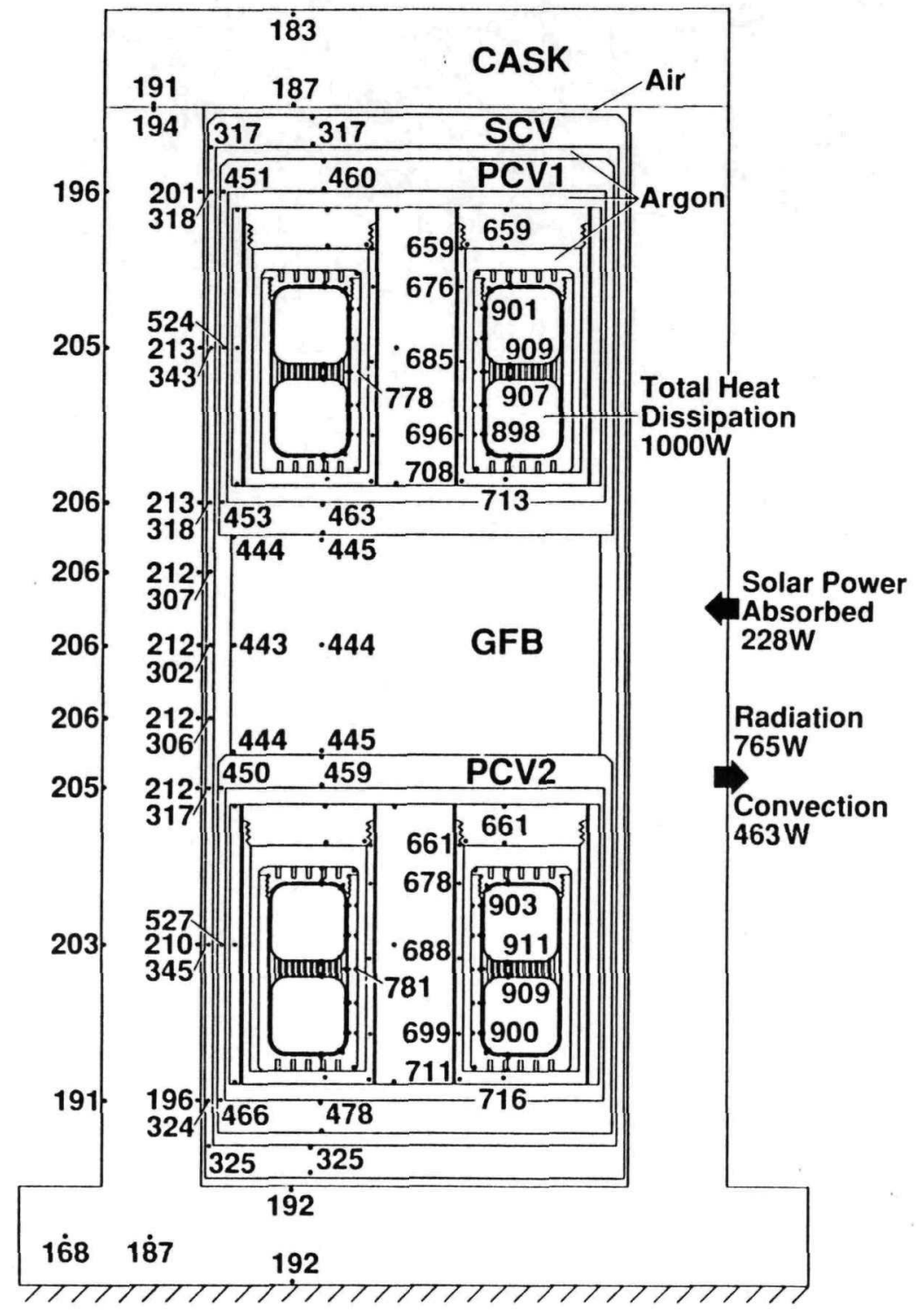

FIGURE 11. Steady State Temperatures of 8-GIS Model, Differential Thermal Expansion Effect Included

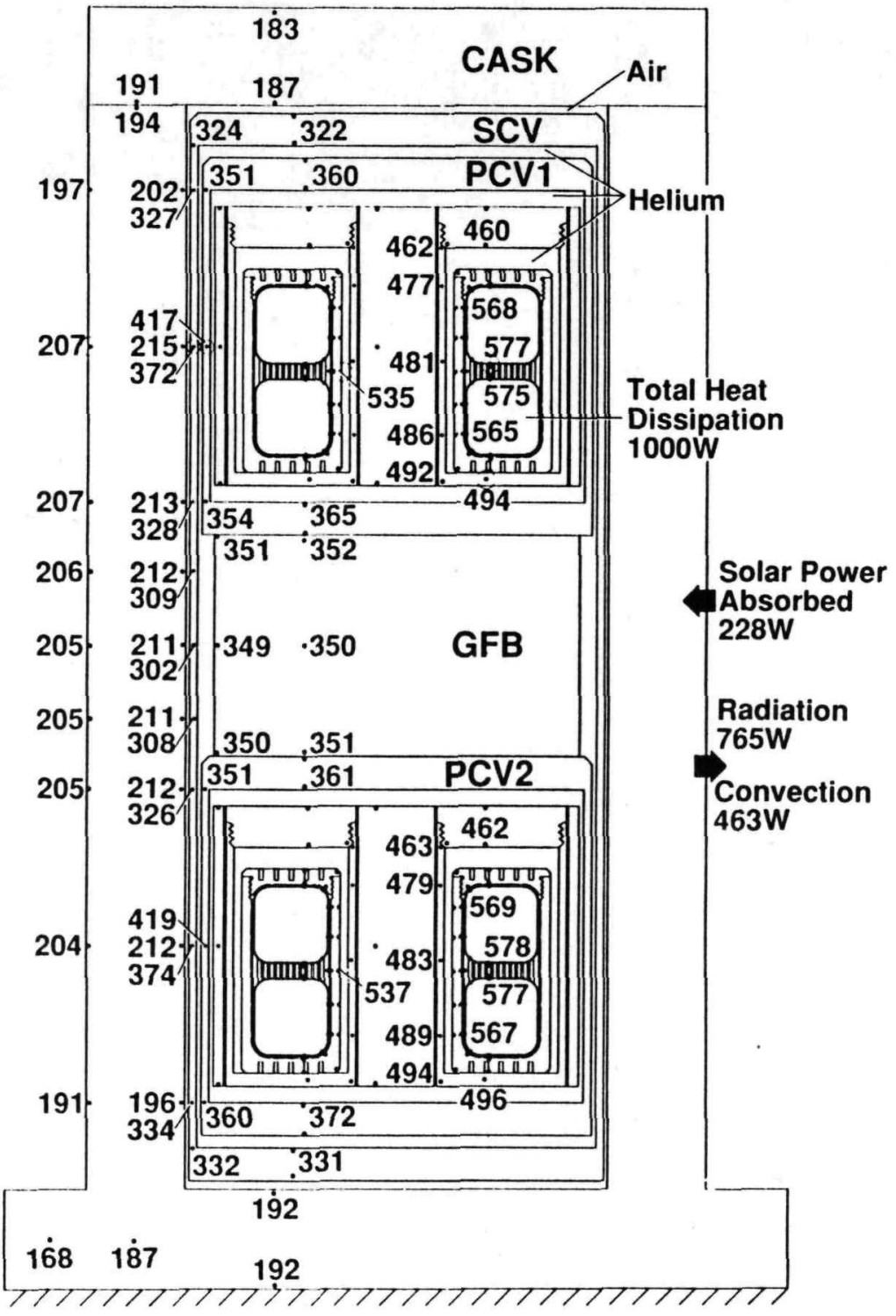

FIGURE 12. Steady State Temperatures of 8-GIS Model, Using Helium as Cover Gas 


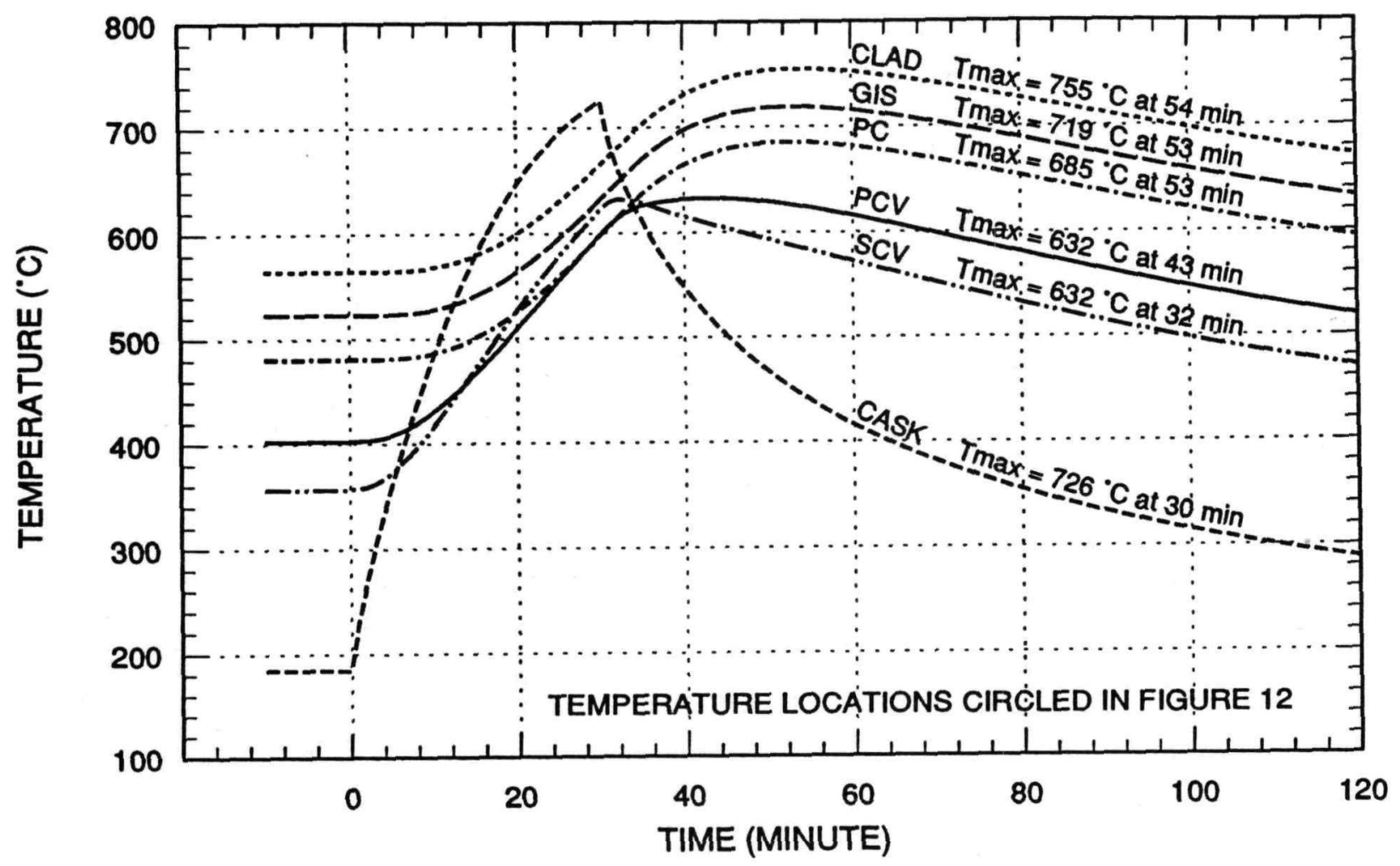

FIGURE 13. Transient Temperatures of 8-GIS Model Using Helium as Cover Gas

\section{Helium Cover Gas in Welding Chamber}

Before all the analyses, Fairchild had made the recommendation to use helium cover gas in the welding chamber. Helium cover gas has been used in the existing facility and so no modification is needed. In NCT, a better conducting cover gas improves heat transfer thru the gap. The steady state temperatures inside the cask will definitely be lower. In HAC, the steady state initial temperatures inside the cask will also be lower. However, the cask will heat up faster in the fire. These $\mathbf{2}$ factors on the transient temperatures are conflicting. Analyses were performed to predict the net effects. In NCT, comparing Figures 12 and 3, the maximum PCV temperature is about $130^{\circ} \mathrm{C}$ lower using helium versus argon. In HAC, comparing Figures 13 and 7 , the maximum PCV temperature is about $70^{\circ} \mathrm{C}$ lower using helium versus argon. These analytical results support that using helium as cover gas provides a bigger safety margin.

\section{CONCLUSIONS}

1. With respect to the PCV or SCV temperatures, the 8-GIS or the 16-clad product can configuration is the worst case.

2. The temperatures predicted for all shipping configurations under NCT and HAC are within design limits.

3. Using helium instead of argon as cover gas provides a bigger safety margin. 


\section{Acknowledgments}

This work is supported by DOE/Office of Special Applications under the supervision of Vince Cassella. The author is in debt to R. Carpenter and E. Skrabek for their continuous guidance. The author would like to thanks Corwin Robinson of EG\&G Mound Applied Technologies and Paul Bales of H\&R Technical Associates, Inc. for providing all the information. Special thanks to $\mathrm{K}$. Yates for her assistance in the preparation of this paper.

\section{References}

Coleman, H. and C. Robinson (1991) Safety Analysis Report for Packaging (SARP) for the Mound $1 \mathrm{~kW}$ Package, EG\&G Mound Applied Technologies, Miamisburg, OH, April 1991.

Coleman, H. and C. Robinson (1992) Safety Analysis Report for Packaging (SARP) for the Mound $1 \mathrm{~kW}$ Package, Revision 3, EG\&G Mound Applied Technologies, Miamisburg, OH, May 1992.

Gaski, J. (1986) SINDA (System Improved Numerical Differencing Analyzed), version 1.23, from Network Analysis Associate, Fountain Valley, CA.

Gebhart, B. (1971) Heat Transfer, Second Edition, McGraw Hill Book Company, Cornell University, NY.

Kays, W.M and M.E. Crawford (1980) Convective Heat and Mass Transfer, Second Edition, McGraw Hill Book Company, Stanford University, CA.

Little (1986) SSPTA (Simplified Space Payload Thermal Analyzer), version 3.0/VAX, by Arthur D. Little Inc., for NASA/Goddard under Contract NAS5-27606, by Arthur D. Little Inc, Cambridge, MA. 